\title{
LOBOSCELIDIINAE, NEW SPECIES AND A NEW
}

GENUS FROM MALAYSIA

(CHRYSIDIDAE, HYMENOPTERA)

\author{
By LYNN SIRI KIMSEY
}

Museum of Comparative Zoology

Harvard University, Cambridge, MA 02138, USA

Loboscelidiinae is one of the most aberrant and poorly understood groups of Chrysididae. Even the family placement of Loboscelidia Westwood has varied considerably over the years. Throughout this entire period, as recounted by Day (1978), none of the authors involved recognized the difference between the sexes. Maa and Yoshimoto (1961) treated them as separate genera, Loboscelidia (males) and Scelidoloba Maa and Yoshimoto (females).

These wasps are strongly sexually dimorphic, making association of the sexes difficult. Males have a long slender flagellum and tend to be less robust looking than females. The female flagellum is short, flattened and broad. In addition, the sexes do not appear to share the same modifications of the face, mesopleuron, legs and scutellum within a species. However, the wing venation and development of the notauli is apparently the same in conspecific males and females. To further complicate matters fewer than $10 \%$ of the specimens in collections are female.

Loboscelidia is characterized by having the antennae insert mid face; head prolonged posteriorly into a necklike projection; pronotum not freely hinged to scutum; tegulae very large, covering both wing bases and held in place by a ridge on the mesopleuron; mesopleuron smooth without sculpturing; propodeum without horizontal dorsal surface and with shelflike lateral projections; forewing lacking a stigma and costal vein, and the abdomen with 4 (females) or 5 (males) external gastral segments.

A complete revision of this group would be premature at this point. However, there are a large number of new taxa in this subfamily, which need to be published in anticipation of a monograph on the family being prepared by myself and R. M. Bohart.

Specimens were borrowed from the following institutions and individuals, type repositories are indicated by capital letters: Academia Sinica, Institute of Zoology Insect Collection, Beijing, 
China (Beijing) American Entomological Institute, Gainesville, Florida, U.S.A. (Gainesville, H. Townes), Australian National Insect Collection, C.S.I.R.O., Canberra City, Australia (CANBerra, J. C. Cardale), Bernice P. Bishop Museum, Honolulu, Hawaii, U.S.A. (Honolulu, G. Nishida), British Museum (Natural History), London (London, M. C. Day), Canadian National Collection, Ottawa, Ontario (Ottawa, L. Masner), Department of Primary Industries Insect Collection, Indooroopily, Queensland, Australia (InDooroopily, K. J. Houston), and Bohart Museum of Entomology, University of California, Davis, USA (DAvis, R. O. Schuster).

\section{Loboscelidia asiana Kimsey, new species}

(Figs. 3, 9)

Holotype male. Body length $3 \mathrm{~mm}$. Frontal projection triangular in front view, appearing truncate in profile (fig. 3); frons smooth with sharp fold extending from frontal projection along ocular margins to vertex; cervical projection slightly convex in profile; scape with narrow transparent flange extending two-thirds scapal length; F-I length $2.4 \times$ breadth; F-II shorter than I, length $2.2 \times$ breadth; pronotum longer than broad along transverse and longitudinal midlines; scutum with complete notauli; propodeal projections angular, less than 1 MOD tall; forewing with faint maculation, R1 0.6X, cu-a $0.3 \times$ and Rs $1.4 \times$ as long as stigmal vein; femora and tibiae with numerous ventral macrochaetae; mid and hindlegs (fig. 9); midfemoral flange extending less than one half as long as femur; midtibial flange narrow, two-thirds tibial length; hindfemoral flange slender, as long as femur; hindtibial posterior margin bicarinate, flange $0.75 \times$ as long as tibia. Body reddish brown, wings maculate.

Female unknown.

Holotype male.-VIET NAM: Dalat, 1500 m, 29 April-4 May 1960, L. W. Quate (HonOLULU).

Discussion. This species is closest structurally to defecta Kieffer, and less so to atra Krombein, based on the V-shaped frontal projection below the antennal sockets, Rs less than half as long as stigmal vein, $\mathrm{R} 1$ and cu-a present and distinct, and F-II more than twice as long as broad. It can be distinguished from these species by the lengths of cu-a and R1 and shape of the frons. 
Loboscelidia australis Kimsey, new species

(Fig. 1)

Holotype male. Body length $2.5 \mathrm{~mm}$. Frontal projection narrow, elongate and apically truncate in front view, forming an acute tooth in profile (fig. 1), and with smaller projection beneath antennal socket; frons smooth, with obtuse fold extending along ocular margin from antennal socket; cervical projection strongly convex in profile; scape with small, short, transparent edge near base; F-I length $1.6 \times$ breadth; F-II length $1.3 \times$ breadth; pronotum as long as broad along transverse and longitudinal midlines; scutum without notauli, parapsides indicated by shallow lines; propodeal projections angular, less than 1 MOD tall; femora and tibiae with few, fine macrochaetae; midtibial flange very narrow extending less than half tibial length; hindfemoral flange large, two-thirds femoral length; hindtibial posterior margin with 1 carina, flange two thirds tibial length; forewing R1 $0.5 \times$, cu-a $0.6 \times$ and Rs $1.3 \times$ as long as stigmal vein. Body reddish brown, somewhat darker on mesopleuron, metathorax and propodeum; wings maculate.

Female unknown.

Holotype male.-Australia: N.S.W., Spencer, 11-14 January (GAinesville).

Discussion. The majority of Australian Loboscelidia, including australis, lack notauli on the scutum. The elongate and noselike subantennal projection of australis will immediately distinguish it from these. Additional diagnostic features include: cu-a slightly more than half as long and R1 half as long as stigmal vein, and hindtibial flange only extending about two-thirds of tibial length.

\section{Loboscelidia indica Kimsey, new species}

(Figs. 2, 6)

Holotype male. Body length $4 \mathrm{~mm}$. Frontal projection broadly bilobate, lower carina forming a narrow rectangle, broadly truncate in profile (fig. 2); frons smooth with sharp fold extending from frontal projection, along ocular margin to hindocellus; cervical projection strongly convex in profile; scape with transparent flange along entire length; F-I and II length $2.2 \times$ breadth; pronotum as long as broad along transverse and longitudinal midlines; scutum 


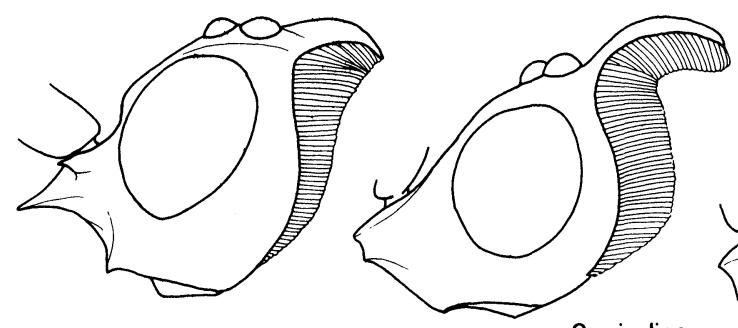

1. australis

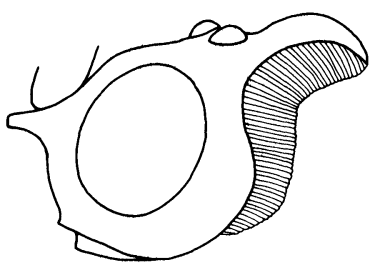

4. ora

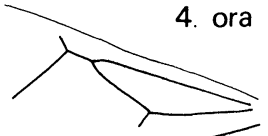

6. indica

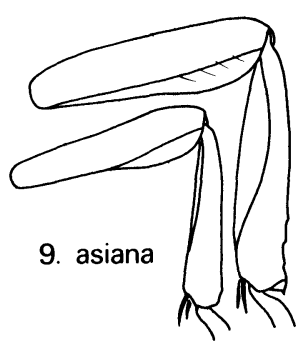

2. indica

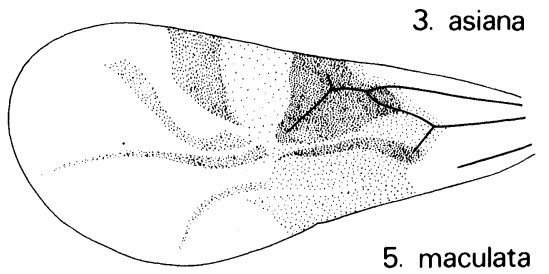

5. maculata
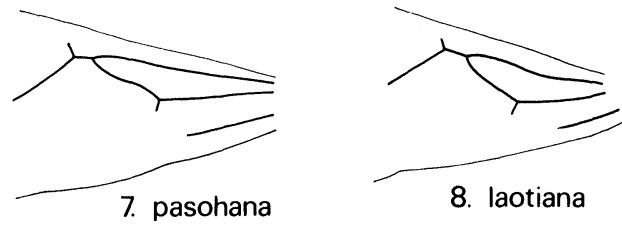

8. laotiana
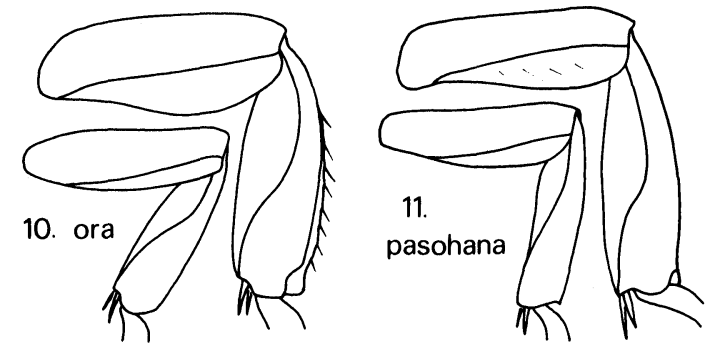

Figs. 1-11. Loboscelidia species. Figs. 1-4. Lateral view of head. Fig. 5. Forewing. Figs. 6-8. Forewing venation. Figs. 9-11. Lateral view of hindleg (above) and midleg (below).

with parapsides and notauli nearly complete; propodeal angles broadly rounded, about 1.5 MOD tall; femora and tibiae with numerous macrochaetae; miditibial flange large, extending over two-thirds of tibia; hindfemoral flange large, extending along twothirds of femur; hindtibial posterior margin bicarinate, flange extending for entire tibial length; forewing (fig. 6), R1 0.6 $\mathrm{x}$, cu-a 
$0.8 \times$ and Rs $2.3 \times$ as long as stigmal vein. Body dark reddish brown, forewing maculate.

Female unknown.

Holotype male.-INDIA: Nilgiri Hills, May 1961, P. S. Nathan (OTTAWA).

Discussion. Closely related to both sarawakensis and philippinensis Fouts, because of the similar wing venation and leg flanges, indica can be distinguished from these species by Rs more than twice as long as the stigmal vein, hindtibial flange extending the entire tibial length, and the subantennal projection broadly truncate and smooth below, without carinae or rugae.

\section{Loboscelidia loatiana Kimsey, new species}

(Fig. 8).

Holotype male. Body length $2.0 \mathrm{~mm}$. Frontal projection broadly triangular in front view, broadly truncate in profile; frons smooth with broadly obtuse fold extending from frontal projection along ocular margin dorsally; scape with narrow flange extending entire length; F-I and II lengths $1.8 \times$ breadths; pronotum broader than long along transverse and longitudinal midlines; scutum with parapsides and complete notauli; propodeal projection angular, more than 1 MOD high; femora and tibiae with sparse macrochaetae; midtibial flange extending two-thirds of tibial length; hindfemoral flange as wide as femur and extending entire length; hindtibial posterior margin bicarinate, flange extending entire length; forewing (fig. 9), R1 0.6X, cu-a $0.4 \times$ and $R s ~ 3 \times$ as long as stigmal vein. Body reddish brown, forewing faintly maculate.

Female unknown.

Holotype male.-Laos: Vientiane Prov., Ban Van Eue, 15 May 1967, native collector (HoNOLulu). Paratypes: 9 males, same data as type, except dates September 1965 to September 1967 (HonoLUlU, Davis); 2 males: VIET Nam: Fyan, 11 July-9 August 1961, N. R. Spencer (Honolulu, Davis).

Discussion. The frontal projection and general wing venation of laotiana are closest to that of pasohana. However, laotiana can be distinguished from pasohana by the shorter Rs vein, smaller average body size ( $2 \mathrm{~mm}$ as opposed to $3 \mathrm{~mm}$ in pasohana), and paler brown color. 


\section{Loboscelidia maculata Kimsey, new species}

(Fig. 5)

Holotype male. Body length $3.5 \mathrm{~mm}$. Frontal projection trilobate in front view with medial lobe elongate and apically truncate, sharply truncate in profile; frons smooth; vertex with short elevated welt on outer side of hindocellus; gena angular behind eye; cervical projection broadly convex in profile; scape with flange extending entire length; F-I-II lengths $1.8 \times$ breadths; pronotum broader than long along transverse and longitudinal midlines; scutum without notauli, parapsides indicated by broad grooves; propodeal projection angulate, less than 1 MOD tall; femora with few macrochaetae; tibiae with numerous ones; midtibial flange extending two-thirds of length; hindfemoral flange extending most of femoral length; hindtibial posterior margin bicarinate, flange extending two-thirds of tibial length; forewing (fig. 5), R1 0.6×, cu-a and Rs $2.2 \times$ as long as stigmal vein. Body dark brown, forewing with dark brown maculae.

Female unknown.

Holotype male.-Australia: Qld., Mulgrave R. Rd., 7 km sw Bellenden Ker, 2 April 1984, A. Calder and T. Weir (CANBerra). Paratypes: 2 males, Mossman Gorge, 17-23 February 1984, L. Masner (OtTaWA); 1 male, Kuranda, 17-24 February 1984, L. Masner (OtTawa); 1 male, Shiptons Flat, 16-18 May 1981, A. Calder and J. Feehan (CANBerRA).

Discussion. The absence of notauli and wing venation indicate a close relationship with ora, and less so australis. L. maculata can be further distinguished from these species by the subantennal projection acutely V-shaped, appearing blunt and truncate in profile, the vertex with a welt or fold on the outer side of the hindocellus, and the wings darkly maculate.

\section{Loboscelidia nigricephala Kimsey, new species}

Holotype male. Body length $3 \mathrm{~mm}$. Frontal projection broadly $V$-shaped in front view, truncate in profile; frons with fine dense scratches or rugae, with short, obtuse lateral fold extending dorsad from frontal projection; cervical projection broadly curved in profile; scape with flange dark, forming large basal lobe; gena broadened behind eye; F-I and II lengths $1.8 \times$ breadths; pronotum broader than long along transverse and longitudinal midlines; scutum with parapsides and incomplete notauli; propodeal angles large and evenly rounded, about 1.8 MOD high; femora and tibiae with 
sparse macrochaetae; midtibial flange extending along two-thirds of tibia; hindfemoral flange large, extending along entire femoral length; hindtibial posterior margin weakly bicarinate, one faint, the other expanded and flangelike, ventral flange large, extending entire length; forewing R1 $0.3 \times$, cu-a as long as and Rs $2 \times$ as long as stigmal length. Body reddish brown, except flagellum, head, leg joints, tarsi and abdomen dark brown, head blackish dorsally; forewing maculate.

Female unknown.

Holotype male.-Australia: Qld., Hugh Nelson Ranch, $21 \mathrm{~km} \mathrm{~s}$ Atherton, 9 January-10 February 1984, Storey and Brown (INDooROOPILY). Paratypes: 6 males, same data as type (INDOOROOPILY, Davis).

Discussion. This is the only Australian species described which has notauli. Other characteristics, particularly the large hindleg flanges, short Rs and long cu-a veins, show a distinct similarity to ora. However, the presence of notauli and contrastingly dark head will distinguish nigricephala. In addition, nigricephala has a pronounced medial carina below the frontal projection.

\section{Loboscelidia ora Kimsey, new species}

(Figs. 4, 10)

Holotype male. Body length $2.5 \mathrm{~mm}$. Frontal projection forming an extremely flattened triangle in front view, narrowly truncate in profile (fig. 4); frons smooth with faint fold extending dorsad from frontal projection along ocular margin; cervical projection broadly curved in profile; scape without clear flange, with brown carina; F-I and II lengths $1.8 \times$ breadths; pronotum as long as broad along transverse and longitudinal midlines; scutum with parapsides indicated by a crease, without notauli; propodeal projection angulate, 1.5 MOD tall; femora and tibiae with sparse macrochaetae; mid and hindlegs (fig. 10); mid and hindtibial and hindfemoral flanges extending almost entire length of respective tibia or femur; hindtibial posterior margin bicarinate, inner carina expanded and transparent, flangelike; forewing $\mathrm{R} 1 \mathrm{0.3 \times}, \mathrm{cu}-\mathrm{a}$ as long as and $\mathrm{Rs}$ $2 X$ as long as stigmal vein. Body reddish brown, forewing maculate.

Female unknown.

Holotype male.-Australia: Qld., Bingil Bay, Cedar Creek, 14 May 1980, I. D. Naumann, J. C. Cardale (CANBerRA). Paratypes: 2 males, same data as type; 1 male, Mission Beach, Laceys Creek, 
17.54S 146.06E, 13-14 May 1980, same collectors (CANBERRA, Davis); 1 male, Petford, 29 April 1976, R. I. Storey (CANBerRa). Non-type material: 9 females were seen from Bribie Is., Millstream Falls National Park, Slacks Creek, Toowomba and Shiptons Flat. These are not designated as paratypes due to the uncertainty in associating the sexes.

Discussion. Diagnostic features of ora include: the absence of notauli, face smooth below frontal projection, frontal projection broadly V-shaped and nearly linear in front view, and head and thorax concolorous. The wing venation most closely resembles that of maculata and nigracephala.

This is one of the few species with associated females. In this particular instance the females have the same wing venation, scutal sculpturing, hindleg flanges, and frontal projection as the males.

\section{Loboscelidia novoguineana Kimsey, new species}

Holotype male. Body length $2.5 \mathrm{~mm}$. Frontal projection nearly linear in front view, triangular in profile; frons with fine dense rugae medially; cervical projection broadly curved in profile; scape with flange indicated as small, subbasal, dark lobe; gena not broaded behind eye; F-I and II lengths $2.3 \times$ breadths; pronotum broader than long along transverse and longitudinal midlines; scutum with parapsides and incomplete notauli; propodeal projection large and evenly rounded, about $1.4 \mathrm{MOD}$ high; femora and tibiae with sparse macrochaetae; midtibial flange narrow, extending about 0.5 tibial length; hindfemoral flange extending along half femoral length; hindtibia weakly bicarinate along posterior margin, flange $0.75 \times$ tibial length; forewing Rs $2 \times, \mathrm{R} 10.5 \times$ and cu-a subequal to stigmal vein length. Body dark brown, forewing weakly maculate, with dark band across Rs and R1.

Female unknown.

Holotype male.-NE New Guinea: East Highlands, Aiyura, 1800-1900 m, 6 January 1965, J. and M. Sedlacek (HonOLULU). Paratypes: 2 males (Honolulu); Karimui, 1080 m, 9 July 1963, M. Sedlacek, New Britain: Gazelle Pen., Mt. Sinewit, 900 m, 5-10 November 1962, Sedlacek (Honolulu).

Discussion. This species most closely resembles nigricephala in wing venation, and the incomplete notauli. The slender hindleg flanges, concolorous head and thorax, and linear frontal projection, 
which lacks carinae or rugae below the antennal sockets, distinguish novoguineana from nigricephala and other species.

\section{Loboscelidia pasohana Kimsey, new species}

(Figs. 7, 11)

Holotype male. Body length $3 \mathrm{~mm}$. Frontal projection with elongate rectangular medial lobe and smaller lateral lobe beneath each antennal socket in frontal view, bilobate in profile; frons smooth, with lateral fold along ocular margin; cervical projection strongly convex; scape with transparent flange along entire length; F-I length $1.6 \times$ breadth; F-II length $1.7 \times$ breadth; gena widened behind eye; pronotum as broad as long along transverse and longitudinal midlines; scutum with parapsides and complete notauli; scutellum with dense striae and ridges laterally; propodeal projection broadly rounded, about 1 MOD high; femora with sparse macrochaetae; mid and hindlegs (fig. 11); midtibial flange extending about two-thirds tibial length; hindfemoral flange extending almost entire length of femur; hindtibial posterior margin bicarinate, flange extending entire length; forewing (fig. 7), R1 0.7 $\times$, cu-a $0.5 \times$ and Rs $4.5 \times$ as long as stigmal vein. Body dark brown, forewing lightly maculate.

Female unknown.

Holotype male.-Malaysia: Pasoh Forest Reserve, Negri Sembilan, 17 April 1980, P. Becker and M. Wong ("E. and M. Becker") (Gainesville). Paratypes: 9 males, same data as type, except dates between April 1978 and April 1980.

Discussion. This species most closely resembles laotiana, from which it can be distinguished by the longer Rs vein (3.5-4.0 $\times$ as long as stigmal vein), larger body size, and darker color. Additional diagnostic features include the presence of a troughlike sulcus below the tegular clip on the mesopleuron, strongly projecting and subtruncate frontal projection, and short F-I.

\section{Loboscelidia sarawakensis Kimsey, new species}

Holotype male. Body length $2.5 \mathrm{~mm}$. Frontal projection acutely $\mathrm{V}$-shaped, truncate in profile; frons smooth, with faint fold extending dorsad from frontal projection along ocular margin; cervical projection curved in profile; scape with clear flange extending along entire length; F-I-II lengths $2 \times$ breadths; pronotum slightly broader than 
long along transverse and longitudinal midlines; scutum with complete notauli, without parapsides; propodeal projection angulate, 1.3 MOD tall; femora and tibiae with sparse macrochaetae; mid and hindtibial and hindfemoral flanges large and extending almost entire length of respective tibia or femur; hindtibal posterior margin weakly bicarinate; forewing R $10.8 \times$, cu-a $0.4 \times$ and Rs $2.5 \times$ stigmal vein length. Body dark reddish brown, forewing maculate.

Female unknown.

Holotype male.-SarawaK: 4th div., Gn. Mulu, 17 September to 23 October 1977, D. Hollis (London). Paratypes (London, Davis): 18 males, same data as type; 2 males, same data as type except 1978 and no collector; 1 male, G. Mulu Pk., Long Pala, 1-6 July 1978, V. F. Eastop; G. Mulu, Mellinau Gorge, Keranges Forest, July 1978, M. Vallack; 10 males, BRUNEI: Labi, mixed dipterocarp forest, 200 m, August-September 1979, I. Gauld; 1 male, Bikit Sulang nr. Lamunin, N. E. Stork; 3 males, N. Borneo: Mt. Kirabalu, 1 April 1964, S. Kueh. In addition, 1 male was seen from Indonesia: Sulawesi, Ulara, Dumoga-Bone.

Discussion. Most closely resembling indica in wing venation, sarawakensis can be distinguished from that species by the larger hindfemoral flange and face with a triangular subantennal projection. Additional diagnostic features are the longitudinally scratched scutellum, face below the frontal projection smooth and ecarinate, and R1 and cu-a subequal in length.

\section{Loboscelidia sinensis Kimsey, new species}

Holotype male. Body length $3 \mathrm{~mm}$. Frontal projection acutely truncate, appearing truncate in profile; frons finely and densely rugose medially, with sharp fold extending from frontal projection along ocular margin; cervical margin broadly rounded; scape without flange; F-I-II lengths $1.8 \times$ breadth; pronotum broader than long along transverse and longitudinal midlines, sharp edged laterally; scutum with complete notauli and parapsides; scutellum coarsely scratched and punctate; propodeal projection subtriangular, about 1.6 MOD tall; femora and tibiae with sparse macrochaetae; midtibial flange narrow, about $0.5 \times$ tibial length; hindfemoral and tibial flanges about $0.7 \times$ as long as respective femur or tibia; hindtibia weakly bicarinate posteriorly; forewing R1 $0.3 \times$, cu-a $0.4 \times$ and Rs $1.8 \times$ stigmal vein length. Body dark reddish brown, wings maculate.

Female unknown. 


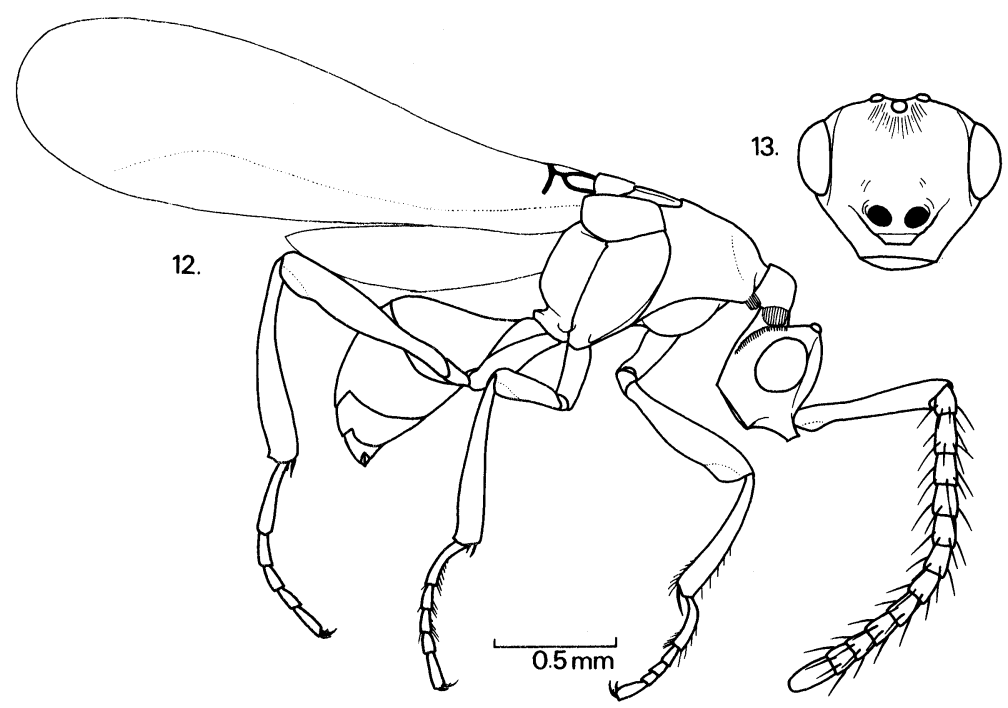

Figs. 12-13. Rhadinoscelidia malaysiae. Fig. 12. Lateral view of body. Fig. 13. Front view of face.

Holotype male.--China: Hainan Is., Tien Fong Mts., 21 May 1983, Z. Bouçek (BeiJing). Paratypes: 3 males, same data as type (LONDON, DAVIS).

Discussion. L. sinensis has the very short $\mathrm{R} 1$ and cu-a veins characteristic of bakeri Fouts, asiana and defecta. However, the coarsely sculptured scutellum, broad and sharp edged pronotum, and acute V-shaped frontal projection separate sinensis from these species.

\section{Rhadinoscelidia Kimsey, new genus}

Diagnosis. Vertex strongly elevated above cervical extension of head; cervical extension constricted behind ocelli and eyes, and posteriorly expanded and shieldlike dorsally, with narrow ovoid row of ribbonlike setae along anterolateral edge of shield; head with narrow postocular row of ribbonlike setae; scape long, flattened and slender, as long as pedicel + F-I-IV; pronotum slender, narrower than head, laterally rounded and somewhat constricted medially, with anterolateral lobe subtended by small tuft of ribbonlike setae; scutum with notauli and posterolaterally lobate; propodeum strongly indented above petiolar insertion, with apical skirt-like rim; 
coxae slender and elongate; tibiae slender and slightly curved, without transparent flanges; forewing venation highly reduced, restricted to basal 1/13th of wing, consisting of Rs, R1, Sc+R, M and $\mathrm{M}+\mathrm{Cu}$, and a stained line and fold indicating 1A; tarsal claws with small medial tooth; body integument smooth and impunctate.

Female unknown.

Etymology: Rhadino-slender, scelidia-legged, f., Gr.

Type: Rhadinoscelidia malaysiae Kimsey, new species.

Discussion. These are small slender wasps, closely related to Loboscelidia. They are characterized by having many reduced characteristics, including the slender cervical projection, narrow wings with reduced venation, small combs of ribbon-like setae on the head and pronotum, and small flanges on the legs. In addition, the bonnet-shaped cervical projection and angulate vertex distinguish this genus from Loboscelidia.

\section{Rhadinoscelidia malaysiae Kimsey, new species}

(Figs. 12, 13)

Holotype male. Body length $2 \mathrm{~mm}$. Frontal projection with truncate medial and lateral lobes in front view (fig. 13), bilobate in profile (fig. 12); frons with dense fine scratches radiating from midocellus; vertex with transverse carina extending from hindocellus to, and part way down ocular margin; scape $1.2 \times$ head length, without transparent flange; F-I $1.6 \times$ as long as broad; F-II length $1.5 \times$ breadth; pronotum longer than broad along transverse and longitudinal midlines, broadly rounded laterally; scutum with parapsides and notauli; propodeal projections angulate and 1 MOD high; femora with small apical flange; tibiae without flanges; hindtibial posterior margin without distinct carinae; forewing R1 $2 \times$ and Rs $3 \times$ as long as stigmal vein (fig. 12). Body reddish brown, with scattered long erect pale setae, forewing with apical third brownstained.

Holotype male.-Malaysia: Pasoh Forest Res., Negri Sembilan, 13 October 1979, P. Becker and M. Wong ("E. and M. Becker") (GAINESVILLE).

Discussion. Diagnostic features of this species are difficult to distinguish from generic characteristics. However, the narrow wings, abbreviated wing venation and slender body will immediately distinguish this species from other loboscelidiines. 
SUMMARY

A number of new taxa are described in the chrysidid subfamily Loboscelidiinae, including 8 new species of Loboscelidia Westwood, asiana, australis, indica, laotiana, maculata, nigricephala, novoguineana, ora, pasohana, sarawakensis and sinensis, and the new genus and species Rhadinoscelidia malaysiae.

ACKNOWLEDGMENT

This study was supported by NSF grant no. BSR-8600341. 

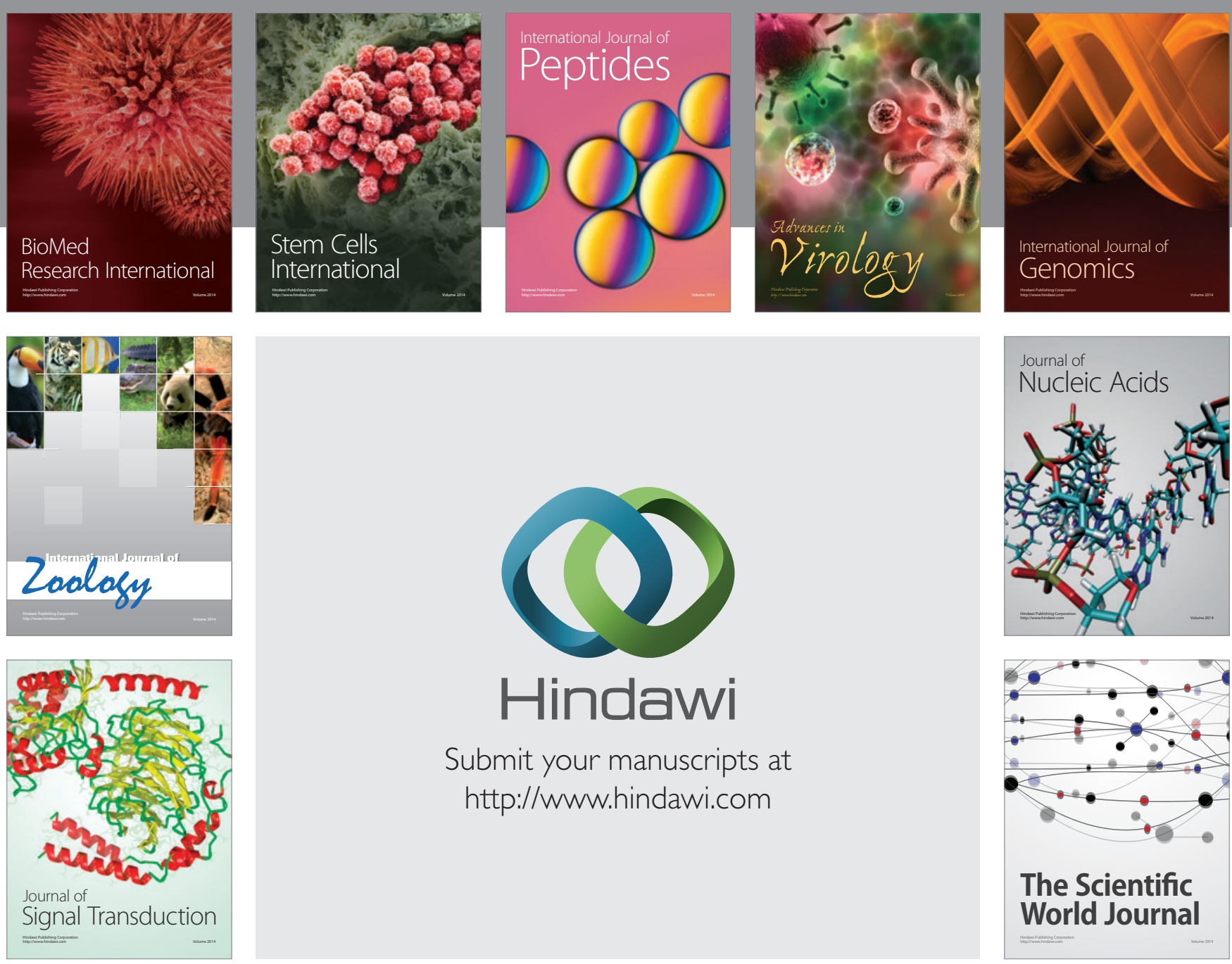

Submit your manuscripts at

http://www.hindawi.com
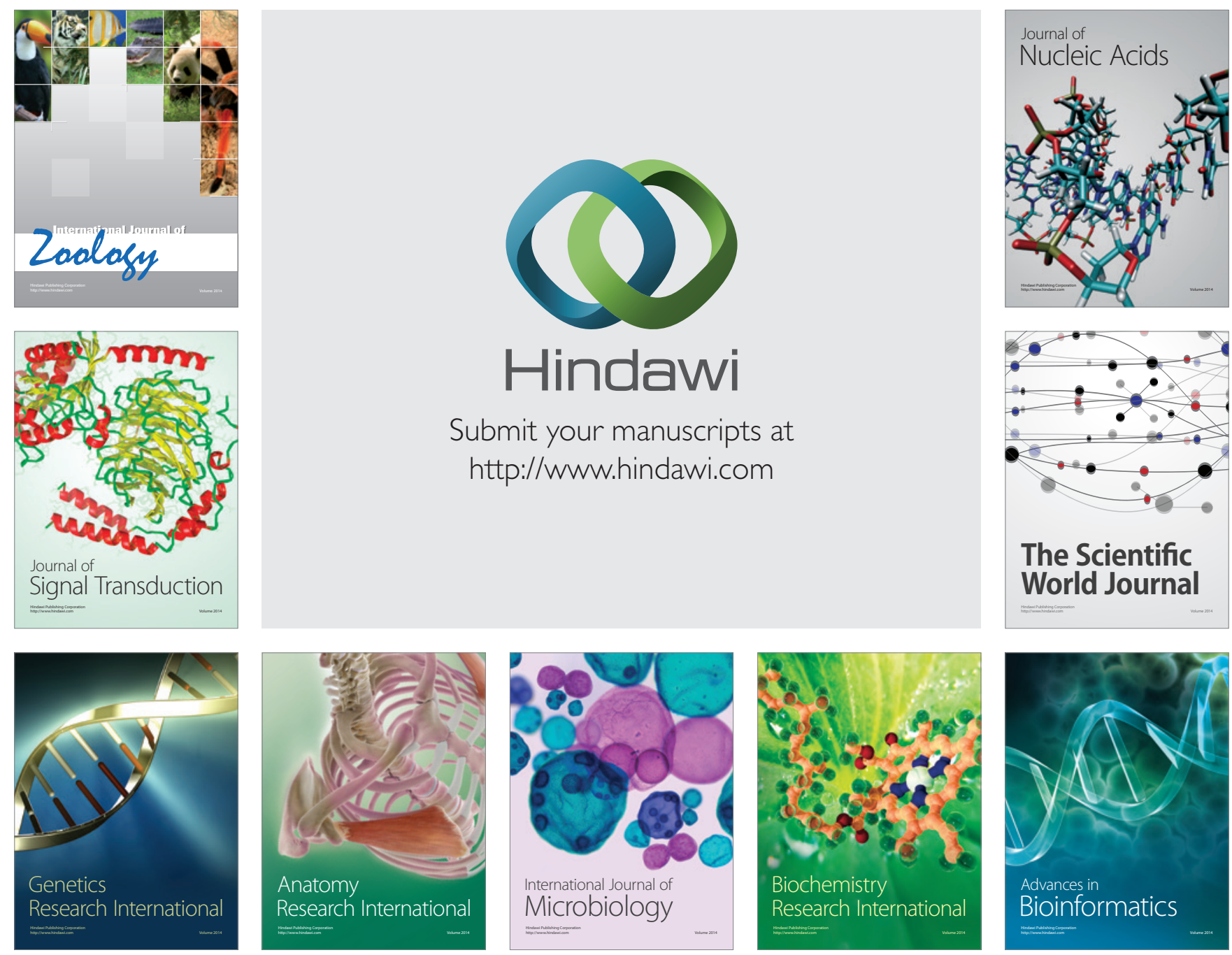

The Scientific World Journal
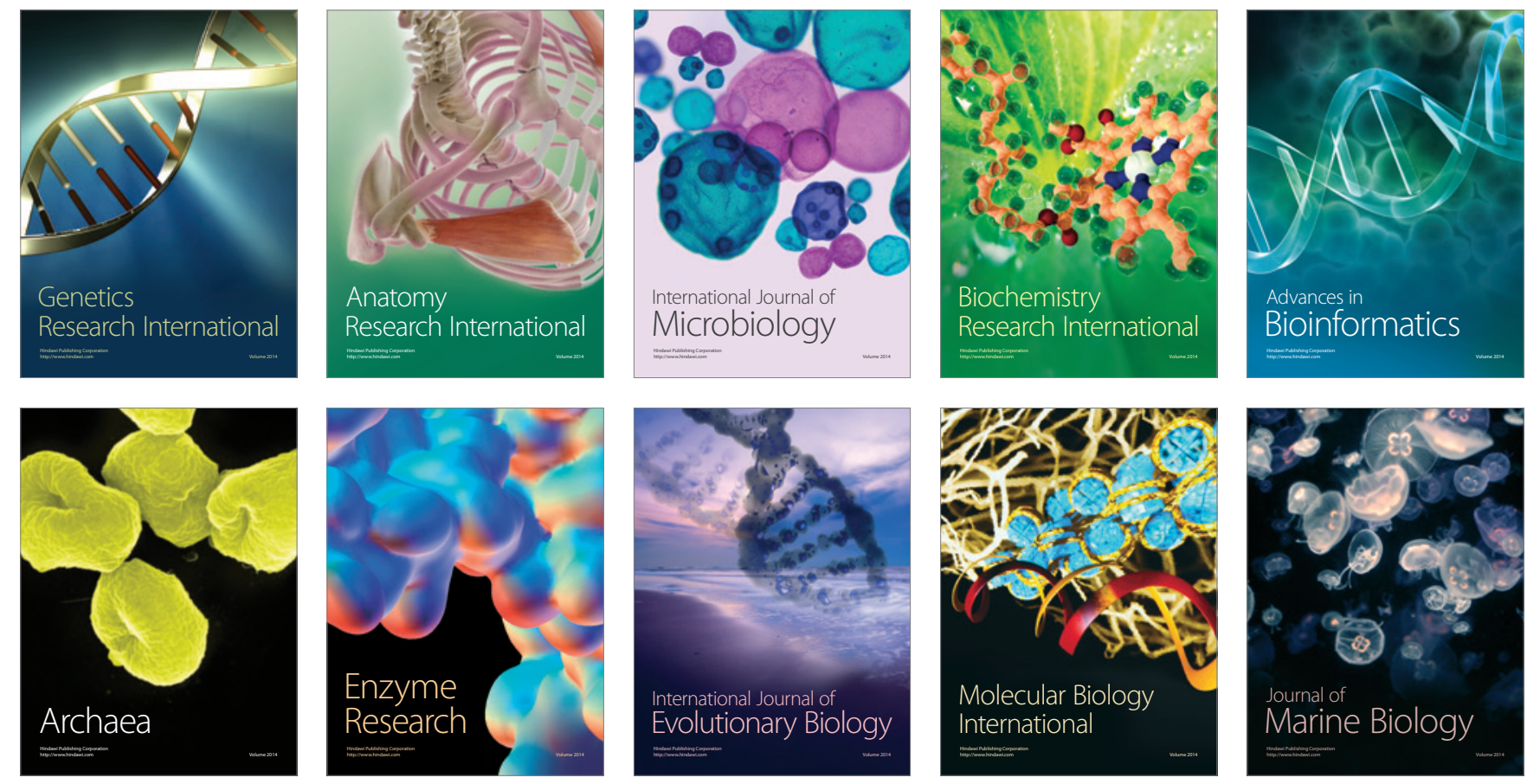